\title{
Development of Ornithine Metabolism in the Mouse Intestine
}

\author{
JACQUES E. RIBY, RUTH E. HURWITZ, AND NORMAN KRETCHMER \\ Department of Nutritional Sciences, University of California, Berkeley, California 94720
}

\begin{abstract}
Circulating arginine available for synthesis of protein is produced in the kidney of the adult mammal by the action of the last two enzymes of the urea cycle, argininosuccinate synthase and argininosuccinate lyase. In a previous publication, we reported the presence of a complete biosynthetic pathway for arginine in the intestine of the neonatal mouse at a time when no other endogenous sources of arginine were available. Our present study was aimed at the determination of the source of ornithine used by the intestine of the neonatal mouse for the synthesis of arginine. We established the developmental profile of the two intestinal mitochondrial enzymes, pyrroline 5-carboxylate synthase and ornithine aminotransferase, responsible for the conversion of glutamate to ornithine. Both enzymatic activities were found to be significantly elevated throughout the suckling period with a peak of activity during the 2 nd wk of life. Glutamate dehydrogenase activity in the intestine did not appear to be developmentally regulated during the suckling and weaning periods; therefore, this enzyme was used as a convenient marker to quantify mitochondrial preparations. Ornithine decarboxylase activity was undetectable in the intestine of the mouse during the suckling period and was detected briefly at weaning, indicating that ornithine synthesized in the intestinal mitochondria is probably not diverted actively into the polyamine pathway and is available for synthesis of arginine by the enzymes of the urea cycle. (Pediatr Res 28: 261-265, 1990)
\end{abstract}

\[ \text { Abbreviations } \]
CPS, carbamyl phosphate synthase
OTC, ornithine transcarbamylase
ASS, argininosuccinate synthase
ASL, argininosuccinate lyase
PCS, pyrroline 5-carboxylate synthase
OAT, ornithine aminotransferase
P5C, pyrroline 5-carboxylate
GDH, glutamate dehydrogenase
ODC, ornithine decarboxylase
HEPES, $N$-2-hydroxyethylpiperazine- $N^{\prime}$-2-ethanesul-
fonic acid

The small intestine of the neonatal mouse possesses all the enzymes necessary to synthesize arginine from ammonia, carbon dioxide, and ornithine, whereas in the intestine of the adult mouse, the synthetic pathway stops with citrulline $(1,2)$. The mitochondrial enzymes, CPS I (EC 6.3.4.16) and OTC (EC

Received December 11, 1989; accepted May 1, 1990.

Correspondence: Dr. Jacques Riby, 308 Morgan Hall, Department of Nutritional Sciences, University of California at Berkeley, Berkeley, CA 94720.

Supported in part by NIH Grants T32-HD07266 and 5P30-HD22224.
2.1.3.3), are found in the intestine of both the adult and the newborn. The enterocyte of the newborn mouse contains the cytosolic enzymes ASS (EC 6.3.4.5) and ASL (EC 4.3.2.1). These enzymes catalyze the synthesis of arginine from citrulline. CPS I and ASL activities in the intestine are highest at birth, with ASL activity almost 7 times greater than that found in the intestine of the adult mouse (1). In the adult mouse, citrulline synthesized by the intestine is delivered to the kidney via the blood stream and converted to arginine by renal ASS and ASL (3-5). Activity of ASL in the kidney of the newborn mouse is $1 / 5$ that of the adult. The activity of this enzyme rises sharply during the suckling period to reach a value nearly twice that in the adult (1).

The ability of the intestine to synthesize arginine is extremely important at birth and during the suckling period, when growth rates are maximum and when the kidney has a limited capability for synthesis of arginine. The only other tissue with significant ASS and ASL activities is the liver. However, the arginine produced in the liver is used exclusively by the hepatic arginase (EC 3.5.3.1) for the production of urea and ornithine (5). In contrast, arginase is totally absent from the small intestine of the newborn mouse and does not appear until weaning (1). A similar finding has been reported for the intestine of the newborn rat $(6,7)$. Large quantities of ornithine in neonatal intestine are needed for two reasons: protein is rapidly synthesized in the intestine at birth and throughout the suckling period, and arginine available for protein synthesis is produced from citrulline synthesized by intestinal mitochondria using ornithine as substrate. In the liver, the ornithine generated by arginase in the last step of the urea cycle reenters the pathway and is constantly recycled (5). In the liver, proline can be converted to ornithine, thus serving as another source for ornithine entering the urea cycle. These pathways are not present in the intestine (8). It had been known for many years that labeled proline and arginine could be isolated from the whole carcass of animals given isotopically labeled glutamate (9), but the site of synthesis could not be located. Smith et al. (10) were the first to show that cultured mammalian cells derived from ovary cells could convert glutamate to P5C, an immediate precursor of proline and ornithine. More recently, Windmueller et al. (5) used luminal and vascular perfusion of ${ }^{14} \mathrm{C}$-glutamine in isolated rat intestine and found formation of large amounts of labeled ornithine, proline, and citrulline. Because the intestine was identified as the site of synthesis of ornithine, Jones and coworkers (11-14) established that in the intestinal mitochondria of the adult rat, ornithine can be synthesized from glutamate via L-glutamyl- $\gamma$-semialdehyde by the enzyme PCS. PCS activity is thought to consist of the combination of two enzymatic reactions: $\gamma$-glutamyl kinase followed by $\gamma$ glutamylphosphate reductase (14). The end product of PCS activity, glutamate- $\gamma$-semialdehyde, is in equilibrium with P5C; the interconversion between these two compounds is spontaneous and does not require any enzymatic action. Glutamate- $\gamma$ semialdehyde is converted to ornithine by OAT (EC 2.6.1.13) (14).

Deficiencies of enzymes in this pathway have been found in some patients with gyrate atrophy of the choroid and retina. This 
pathology has been shown to result from a mutation of the structural gene for OAT. In this disease, high concentrations of blood ornithine were associated with low concentration of proline (15). Faulty ornithine metabolism has also been found in obligate carnivores, such as cats and ferrets, which have an obligatory requirement for dietary arginine. When fed a diet deficient in arginine, these animals develop clinical signs of cyanosis, hyperammonemia, and orotic aciduria and eventually die within a few hours. Morris (16) found that the activity of both PCS and OAT in the intestines of these animals was very low compared with that in rats. Low synthesis of ornithine in carnivores results in deficient entry of citrulline into the urea cycle, and consequently, excretion of ammonia is poor.

We established the developmental profiles of the enzymatic activities catalyzing the conversion of glutamate to ornithine to identify the source of ornithine necessary for synthesis of citrulline in the intestine of the newborn and the suckling mouse. The developmental profile of ODC was also studied to ascertain whether the newly synthesized ornithine was diverted into the pathway for synthesis of polyamines.

\section{MATERIALS AND METHODS}

Animals. Mice of the C57Bl/6 strain were bred in our animal facilities and were fed laboratory mouse chow (Ralston-Purina Co., St. Louis, MO; 5015) ad libitum. The adult mice used in this study were 2-6 mo of age. The mice were killed between 0900 and $1000 \mathrm{~h}$ by decapitation or cervical dislocation. Animal care and procedures were carried out in accordance with $\mathrm{NIH}$ guidelines after review and approval by the Animal Care and Use Committee of the University of California at Berkeley under the Animal Use Protocol no. R89-0431-0690R.

Preparation of tissues. The small intestine from adults was removed and quickly flushed with isotonic PBS at $0^{\circ} \mathrm{C}$. The duodenum was discarded, and the remaining part of the intestine was slit open and laid flat on a glass plate resting on ice. The mucosa was scraped off with a microscope slide, weighed, and immediately homogenized. The small intestine from newborn and suckling animals was homogenized whole after the duodenum had been removed.

Isolation of mitochondria. PCS activity could be assayed only in isolated mitochondria. Attempts to use whole tissue homogenate resulted in the incorporation of the ${ }^{14} \mathrm{C}$ label from $\left[1-{ }^{14} \mathrm{C}\right]$ glutamate into a product that coeluted with glutamine on a AG50W-X8 ion exchange column (Bio-Rad Laboratories, Richmond, CA). Mitochondrial fractions were isolated by the method developed by Wakabayashi and Jones (14) for rat intestine. GDH was used as a mitochondrial marker to ascertain that the yield and purity of the mitochondria preparation were consistent for animals in different age groups. Mucosal scrapings from individual adults $(0.3-0.4 \mathrm{~g})$ or whole small intestines from sucklings were pooled to constitute the same amount of tissue (typically: 6-8 at d 1, 4-5 at d 6, 3-4 at d 13, etc.) and were homogenized in $10 \mathrm{~mL}$ of homogenization buffer ( 5 mM HEPES pH 7.4, 300 $\mathrm{mM}$ mannitol, $3 \mathrm{mM}$ DTT, $0.2 \mathrm{mM}$ EDTA) at $0^{\circ} \mathrm{C}$ using a loose-fitting Teflon pestle, by six strokes at minimum speed. The homogenate was transferred to a beaker containing $5 \mathrm{~mL}$ of fine glass beads $(0.15 \mathrm{~mm}$ diameter) rinsed in homogenization buffer. The homogenizer was rinsed with $5 \mathrm{~mL}$ of the same buffer, and that buffer was added to the homogenate. The suspension was stirred with glass beads at $0^{\circ} \mathrm{C}$ for $5 \mathrm{~min}$. The glass beads were then removed by decantation, and the homogenate was transferred to a centrifuge tube. The beads were rinsed twice with 10 $\mathrm{mL}$ of homogenization buffer. After decantation, these rinses were added to the homogenate in the centrifuge tube. EDTA was then added to a final concentration of $5 \mathrm{mM}$. The homogenate was centrifuged at $600 \times \mathrm{g}$ for $10 \mathrm{~min}$ at $4^{\circ} \mathrm{C}$. The supernate was collected and kept on ice while the pellet was suspended in 35 $\mathrm{mL}$ of fractionation buffer (5 mM HEPES pH 7.4, $300 \mathrm{mM}$ mannitol, 0.1 mM DTT, $5 \mathrm{mM}$ EDTA) and centrifuged at 600 $\times \mathrm{g}$ for $10 \mathrm{~min}$. The two supernatant fractions were combined, filtered through fine nylon mesh, and centrifuged at $600 \times \mathrm{g}$ for $5 \mathrm{~min}$. The supernate was centrifuged at $12000 \times \mathrm{g}$ for $15 \mathrm{~min}$. The pellet was suspended in $35 \mathrm{~mL}$ of fractionation buffer and centrifuged at $6000 \times \mathrm{g}$ for $10 \mathrm{~min}$. The final pellet, consisting of a subcellular fraction enriched in mitochondria, was suspended in $2 \mathrm{~mL}$ of the same buffer and assayed immediately for PCS and GDH activities.

Determination of $G D H$ activity. GDH was assayed by a modification of the method described by Beaufay et al. (17). In a total volume of $1.5 \mathrm{~mL}$, the reaction mixture contained: $20 \mathrm{mM}$ potassium phosphate $\mathrm{pH} 7.7,0.13 \mathrm{mM}$ sodium glutamate, 30 $\mathrm{mM}$ niacinamide, $0.1 \%$ Triton $\mathrm{X}-100,0.4 \mathrm{mM}$ potassium cyanide, $1.0 \mathrm{mM}$ cysteine, and $1.4 \mathrm{mM}$ NAD. The reaction mixture was preincubated at $25^{\circ} \mathrm{C}$, and the reaction was started by the addition of $200 \mu \mathrm{L}$ of homogenate or mitochondrial preparation. The production of NADH was measured in a recording spectrophotometer at $340 \mathrm{~nm}$. The reference cell contained all reagents and the sample but no glutamate. GDH activity was expressed as $\mu \mathrm{mol}$ of NADH produced per min.

Determination of PCS activity. PCS was assayed by the method of Wakabayashi et al. (18). In a total volume of $1.0 \mathrm{~mL}$, the reaction mixture contained: $90 \mathrm{mM}$ potassium HEPES $\mathrm{pH} 7.4$, $3 \mathrm{mM}$ ATP, $20 \mathrm{mM}$ magnesium chloride, $15 \mathrm{mM}$ phosphocreatine, $15 \mathrm{U}$ creatine phosphokinase, $0.2 \mathrm{mM}$ NADPH, $7.5 \mathrm{mM}$ isocitrate, $0.45 \mathrm{U}$ isocitrate dehydrogenase, $1 \mathrm{mM} \mathrm{L}-\left[\mathrm{U}_{-}{ }^{14} \mathrm{C}\right]$ glutamic acid $(1.0 \mathrm{Ci} / \mathrm{mol})$, and the mitochondrial suspension (200-400 $\mu \mathrm{g}$ protein) in fractionation buffer with $0.5 \%$ Triton $\mathrm{X}-100$. The reaction started with the addition of the mitochondrial preparation. After incubation at $15^{\circ} \mathrm{C}$ for $20 \mathrm{~min}$, the reaction was stopped by the addition of $150 \mu \mathrm{L}$ of $0.8 \mathrm{M}$ sodiumpotassium glycine pH 10.0. Fifty $\mu \mathrm{L}$ of $240 \mathrm{mM} \mathrm{NaBH}_{4}$ in 5 $\mathrm{mM} \mathrm{NaOH}$ was added to reduce P5C to proline, and the tubes were allowed to stand at room temperature for $20 \mathrm{~min}$. After addition of $50 \mu \mathrm{L}$ of $200 \mathrm{mM}$ carrier proline, the tubes were boiled for $5 \mathrm{~min}$ and the denatured proteins were removed by centrifugation for $10 \mathrm{~min}$ in an Eppendorf microcentrifuge. The supernatants were transferred to $0.7 \times 4.0 \mathrm{~cm} \mathrm{AG1-X8}$ ion exchange columns (Bio-Rad Laboratories) equilibrated with water to remove the unused ${ }^{14} \mathrm{C}$-glutamate. The eluates containing the ${ }^{14} \mathrm{C}$-proline were collected directly into scintillation vials and the columns were rinsed with an additional $3 \mathrm{~mL}$ of water. Samples were measured for ${ }^{14} \mathrm{C}$ by liquid scintillation after addition of $15 \mathrm{~mL}$ of Ecoscint-A (National Diagnostics Inc., Manville, NJ). Blanks were obtained for each assay by omitting ATP and the ATP-regenerating system (phosphocreatine and creatine phosphokinase) in the incubation mixture. PCS activity was expressed as $\mu \mathrm{mol}$ of P5C produced per min.

Determination of OAT activity. OAT was assayed by a modification of the method of Peraino and Pitot (19). P5C was formed by OAT from the substrates ornithine and $\alpha$-ketoglutarate and produced a yellow-colored compound in the presence of $o$ aminobenzaldehyde. Incubation mixture contained $50 \mathrm{mM}$ potassium phosphate $\mathrm{pH} 7.5,30 \mathrm{mM}$ ornithine, $50 \mathrm{mM}$ pyridoxal phosphate, $25 \mathrm{mM} \alpha$-ketoglutarate, and $5 \mathrm{mM} o$-aminobenzaldehyde in a total volume of $1.0 \mathrm{~mL}$. The reaction was started by the addition of $100 \mu \mathrm{L}$ of homogenate or mitochondrial suspension to the reaction mixture preincubated at $37^{\circ} \mathrm{C}$. After $30 \mathrm{~min}$ at $37^{\circ} \mathrm{C}$, the reaction was stopped by the addition of $0.4 \mathrm{~mL} 15 \%$ trichloroacetic acid and the tubes were allowed to stand at room temperature for $20 \mathrm{~min}$. Precipitated proteins were then removed by centrifugation at $12000 \mathrm{rpm}$ for $5 \mathrm{~min}$ in an Eppendorf centrifuge. The yellow supernatants were measured photometrically at $440 \mathrm{~nm}$. Blanks contained all reagents and samples except $\alpha$-ketoglutarate. P5C standards prepared in the same mixture and processed in the same manner were used to calculate $\mathrm{P} 5 \mathrm{C}$ formed. OAT activity was expressed as $\mu \mathrm{mol}$ of P5C produced per $\mathrm{h}$.

Determination of $O D C$ activity. ODC activity was measured using the production of ${ }^{14} \mathrm{CO}_{2}$ from $\mathrm{L}-\left[1-{ }^{14} \mathrm{C}\right]$ ornithine by a 
modification of the method of Seidel et al. (20). Intestinal mucosa from adults or whole small intestines from sucklings were homogenized individually with nine volumes of buffer containing $100 \mathrm{mM}$ sodium-potassium phosphate at $\mathrm{pH} 5.2,5 \mathrm{mM}$ sodium fluoride, $10 \mu \mathrm{M}$ EDTA, $2 \mathrm{mM}$ DTT, $100 \mu \mathrm{M}$ pyridoxal phosphate, and $0.02 \%$ Tween-20. Homogenates were centrifuged at $30000 \times \mathrm{g}$ for $30 \mathrm{~min}$ at $4^{\circ} \mathrm{C}$, and the supernatants were assayed immediately. One $\mathrm{mL}$ of supernate was transferred to a test tube and brought to $37^{\circ} \mathrm{C}$. The reaction was started by the addition of $0.5 \mu \mathrm{Ci} \mathrm{L}-\left[1-{ }^{14} \mathrm{C}\right.$ ]ornithine $(50 \mathrm{mCi} / \mathrm{mmol})$ in $200 \mu \mathrm{L}$ of homogenization buffer, and the tubes were closed immediately with a rubber stopper. After $30 \mathrm{~min}$ at $37^{\circ} \mathrm{C}$, the incubation was stopped by injecting $1.0 \mathrm{~mL} 3 \mathrm{~N} \mathrm{H}_{2} \mathrm{SO}_{4}$ through the rubber stopper, and the tubes were shaken vigorously for $1 \mathrm{~h}$ at room temperature to allow complete absorption of the $\mathrm{CO}_{2}$ onto a 1 $\times 4 \mathrm{~cm}$ strip of filter paper moistened with $50.0 \mu \mathrm{L} 2 \mathrm{~N} \mathrm{NaOH}$ and suspended in a center well above the reaction mixture. The strips of filter paper were then transferred to scintillation vials with $10.0 \mathrm{~mL}$ of Ecoscint A (National Diagnostics Inc.). ODC activity was expressed as pmol of ${ }^{14} \mathrm{CO}_{2}$ released per $\mathrm{h}$.

Protein concentration of homogenates and mitochondrial preparations were determined according to Lowry et al. (21), using BSA as a standard. All enzymatic assays were done in duplicate, and results were averaged after subtraction of the corresponding blanks. In Figure $1 A-C$, activities are presented as mean \pm SEM for separate determinations on four groups of animals at each time point.

\section{RESULTS}

Preparation of mitochondria. The effectiveness of the method for isolation of mitochondria from the intestine of animals in different age groups was monitored using the mitochondrial marker enzyme GDH. There was no significant difference in the yield of mitochondria recovered in the final fractions from animals of different ages. The mitochondrial fraction typically contained $30 \%$ of the activity of GDH found in the whole homogenate of intestine from the newborn, the suckling, or the adult mouse. That fraction also consistently constituted $5 \%$ of the total protein from the homogenate. Thus, there was a 6-fold purification of the mitochondria. The determination of the pu-
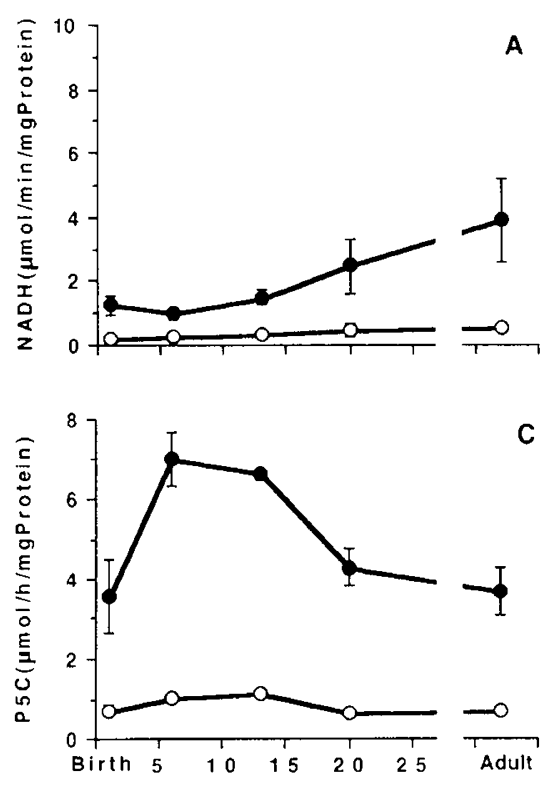

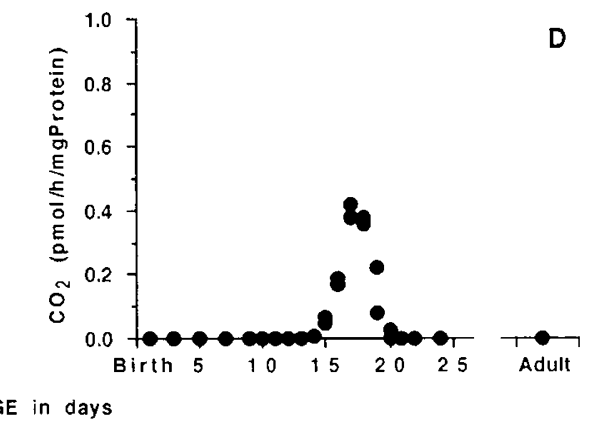

rification factor for each mitochondrial preparation was necessary for the measurement of PCS because this enzymatic activity could be assayed only in isolated mitochondria.

Developmental profile of $G D H$. The developmental profile of GDH is shown in Figure $1 A$. Sp act of GDH rose steadily through the suckling and weaning periods. At birth, the activity was $1 / 3$ the activity in the adult, and by $3 \mathrm{wk}$, it had reached about $2 / 3$ the activity in the adult. This particular mitochondrial enzyme is not involved in the developmental changes affecting the metabolism of ornithine and therefore constitutes a convenient marker for the quantitation of the mitochondrial preparations.

Development of PCS. PCS activity was measured only in the isolated mitochondria. $\mathrm{Sp}$ act in the homogenate was calculated using the purification factor of GDH for each preparation separately. Figure $1 B$ shows that the sp act of PCS at birth was more than twice that in the adult and that during the suckling period (1-2 wk of age), the activity of the enzyme was more than 5 times the activity in the adult. By the end of the weaning period, the activity of the enzyme dropped to the adult value.

Development of OAT. Sp act of OAT was measured in both the total homogenate and the mitochondrial preparation (Fig. $1 C)$. The fact that $\mathrm{sp}$ act in the mitochondrial preparation in all age groups was 5- to 6-fold that of the crude homogenate indicates that OAT is indeed a mitochondrial enzyme and confirms the results obtained with GDH. Sp act in the total homogenate was essentially the same at birth, at the end of weaning, and in the adult. The activity of OAT in mitochondria was markedly elevated at 1 and 2 wk of age.

Development of $O D C$. ODC activity was measured directly in fresh $30000 \mathrm{~g}$ supernatants of $10 \%$ (wt/vol) homogenates (Fig. $1 D)$. We found no measurable activity in the intestine of the newborn or adult mouse. The only substantial activity was found during the $3 \mathrm{rd}$ wk of life, as a temporary spurt of activity accompanying the maturation that occurs at weaning when the intestinal mucosa changes from the suckling type into the adult type.

\section{DISCUSSION}

Inhibition of the synthesis of citrulline in the intestine causes severe growth retardation in young weaned rats (22). Wind-

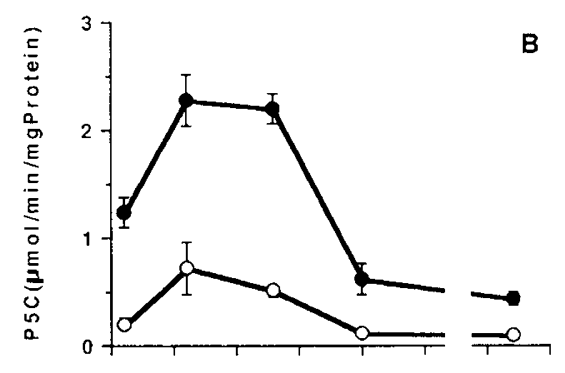

.

AGE in days

Fig. 1. Developmental profile of four enzymatic activities in the small intestine of the mouse: GDH $(A)$, PCS $(B)$, OAT $(C)$, and ODC $(D)$. In $A-C$, closed circles represent sp act in the mitochondrial preparations and open circles represent sp act in the total homogenate. Results are expressed as mean \pm SEM of separate determinations on four groups of animals at each time point. In $D$, closed circles represent sp act of ODC in the cytosolic fraction. Results shown are individual determinations, except in adults where separate determinations on four animals have been combined. 
mueller and Spaeth (5) showed that in the adult most of the conversion of citrulline to arginine takes place in the kidney and that the amount of citrulline taken up by the kidney is proportional to the amount released by the intestine. However, activity of ASL in the neonatal kidney is $1 / 5$ that of the adult, thus limiting its ability to synthesize arginine (1). Hurwitz and Kretchmer (1) showed that the intestine in the neonatal mouse has elevated ASS and ASL activities, thus establishing that a complete biosynthetic pathway for arginine exists in the intestine (Fig. 2). By the 2nd wk of life, intestinal ASL drops significantly, and by the time the young mouse is weaned at $3 \mathrm{wk}$ of age, the activity is essentially down to the adult value. Meanwhile, from birth to 12 $\mathrm{d}$ of age, the activity of renal ASL increases rapidly from $1 / 5$ of the activity of the adult to nearly twice the adult value (1). Whether the last steps of synthesis of arginine take place in the intestine of the newborn mouse or in the kidney of the mature mouse, the substrate used for this synthesis is the citrulline produced by the intestinal mitochondria.

The mitochondrial enzyme CPS I has an activity 3 times higher in the intestine of the newborn than in the intestine of the adult, indicating a potentially increased ability of neonatal intestine to synthesize citrulline (1). Activity of OTC is not higher in the intestine at birth, but that enzyme is not the rate-limiting factor in the pathway (1). To synthesize the large amount of citrulline needed for arginine synthesis during the neonatal period, the intestinal mitochondria need correspondingly large amounts of ornithine. If newly synthesized arginine is to be used for protein synthesis, this amino acid clearly cannot be the substrate for synthesis of ornithine [Fig. 2 (10)]. In addition, arginase is not detectable in the intestine until the $3 \mathrm{rd} \mathrm{wk}$ after birth $(1,6)$. The intestine of the adult rat can synthesize ornithine from glutamate $(11-14)$ [Fig. $2(2,4,6)$ ]. Glutamate is first converted to L-glutamyl- $\gamma$-semialdehyde by the mitochondrial

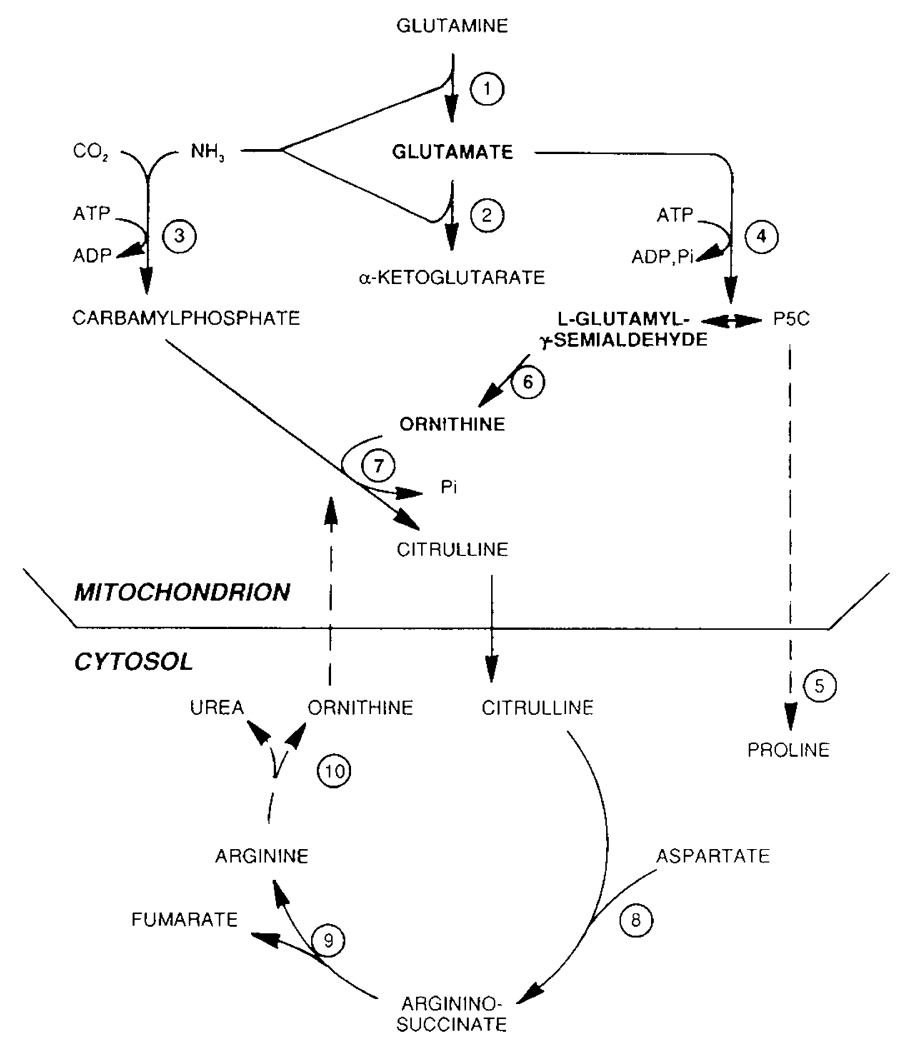

Fig. 2. Conversion of glutamate to citrulline and arginine via ornithine in the intestinal mucosa of the neonatal mouse. Dotted lines indicate activities that are present in the adult mouse intestine but are absent or reduced at birth. 1, glutaminase; 2, GDH; 3, carbamyl phosphate synthase; 4, PCS; 5, P5C reductase; 6 , OAT; 7, OTC; 8 , ASS; 9 , ASL; and 10 , arginase. enzyme PCS [Fig. 2 (4)] $(11,12)$. L-Glutamyl- $\gamma$-semialdehyde and a second molecule of glutamate are then used as substrates by OAT to produce $\alpha$-ketoglutarate and ornithine [Fig. 2 (6)] $(13,14)$. Glutamate is readily available in the intestinal cell as one of the intermediates in glutamine metabolism. Glutamine is metabolized by mitochondrial glutaminase (23) and serves as the major source of energy for the intestinal mucosa. Herzfield and Raper (7) found that OAT activity was elevated and that P5C reductase in the small intestine of the rat was low during the entire suckling period, indicating that at this particular stage of development the conversion of glutamate to ornithine via P5C could supply that substrate for synthesis of citrulline (Fig. 2).

The development of ornithine metabolism in the intestine was previously investigated in the rat (6), but neither the developmental curve of PCS nor the ability of the intestine of the neonatal mouse to synthesize ornithine had been established. The major difficulty in our study was isolation of mitochondria from the small intestine of newborn mice for measurement of PCS. The method developed by Wakabayashi and Jones (14) for isolation of mitochondria from the intestinal mucosa of the rat proved to be quite effective with these newborn mice. Two of the mitochondrial enzymes, GDH and OAT, were systemically assayed in both the total homogenate and the mitochondrial fraction and can therefore be used as mitochondrial markers. Both enzymes showed the same ratio of sp act between homogenate and isolated mitochondria. This result supported the reliability of the isolation method and showed that there was virtually no loss of enzymatic activity during the procedure. There was a $30 \%$ yield of mitochondria at all ages. Sp act of the two markers increased 6-fold during the isolation of the mitochondria, indicating that in all age groups the mitochondrial fraction represents approximately $17 \%$ of the total protein of the intestinal mucosa. Consequently, the potential for de novo synthesis of ornithine by the intestine of the neonatal mouse follows the same pattern as the developmental curve of PCS and OAT activities relative to the mitochondrial protein. If there had been large differences in the relative size of the mitochondrion between any of the various age groups, the differences in sp act of ornithine-synthesizing enzymes might not necessarily have reflected corresponding changes in the overall synthetic capacity. Our results show high activities of PCS and OAT during the suckling period, demonstrating the potentiality for de novo synthesis of ornithine from glutamate (Fig. 2). GDH, a mitochondrial marker, is not involved in the pathway leading to the synthesis of ornithine and citrulline.

In a previous report on synthesis of arginine in the developing mouse intestine (1), we showed that CPS I and ASL were more active at birth when the need for arginine was also high. The shape of the developmental curves expressed the change in ability of the intestine to synthesize arginine when its availability from other sources was minimal and developing slowly during the suckling period. The profile of the developmental curves of the ornithine-synthesizing enzymes presented here show that the activities of PCS and OAT, unlike CPS I and ASL, reach their maximum after $1 \mathrm{wk}$ of life. Because ornithine is essential for the synthesis of citrulline and ultimately arginine, there must be some other source of arginine before birth. Preliminary results in our laboratory (data not shown) indicate that the concentration of ornithine in the plasma is higher in the neonatal mouse than in the adult. Ornithine was higher in fetal blood than in maternal blood. These results are consistent with an active transfer of ornithine through the placenta as in the case of essential amino acids (24). At birth, the concentration of ornithine in the plasma was still higher than in adults, thus delaying the need for increased de novo synthesis.

Activity of ODC and concentration of polyamines in a tissue have often been associated with active cellular multiplication and tissue growth (25). More recently, investigators have found that ODC activity correlates better with the maturation of tissues and the changes in the set of characteristics expressed when a 
cell type is replaced by another type with a different maturational state. ODC activity is typically elevated during regeneration of an organ after injury, during recovery from drug poisoning, or at the onset of a neoplasm (26-29). Previous reports showed ODC activity to be found temporarily in the intestine of the rat during weaning, correlating with the maturation of the intestinal mucosa from the suckling type to the adult type (30-32). To assess whether any of the newly synthesized ornithine was being used for the production of polyamines, we determined the pattern of ODC activity in the small intestine of the developing mouse. Our results are essentially identical to what was found in the rat intestine, showing only a brief spurt of activity at the time of weaning and no detectable activity at any other time. Even at its peak, ODC activity was very low (pmol/h), and the pattern of activity was totally unrelated to the de novo synthesis of ornithine from glutamate.

Our results indicate that in the intestine of the newborn and suckling mouse the enzymes necessary for the synthesis of ornithine from glutamate are more active than those in the intestine of the adult mouse. The potentially elevated synthetic capability correlates with the important need of ornithine for arginine synthesis due to rapid rate of protein synthesis during the developmental period. Ornithine does not appear to be used for the synthesis of polyamines by ODC and, therefore, this substrate is also available for synthesis of arginine.

\section{REFERENCES}

1. Hurwitz R, Kretchmer N 1986 Development of arginine-synthesizing enzymes in mouse intestine. Am J Physiol 251:G103-G110

2. Kretchmer N, Hurwitz R 1989 Nitrogen metabolism in the intestine. In: Halsted H, Rucker RB (eds) Nutrition and the Origins of Disease. Academic Press, New York, pp 309-320

3. Borsook H, Dubnoff JW 1941 The conversion of citrulline to arginine in kidney. J Biol Chem 141:717-738

4. Ratner S, Morell H, Carvalho E 1960 Enzymes of arginine metabolism in brain. Arch Biochem Biophys 62:280-289

5. Windmueller HG, Spaeth AE 1981 Source and fate of circulating citrulline. Am J Physiol 241:E473-E480

6. Herzfeld A, Raper SM 1976 Enzymes of ornithine metabolism in adult and developing rat intestine. Biochim Biophys Acta 428:600-610

7. Herzfeld A, Raper SM 1979 Effects of cortisone or starvation on the activities of four enzymes in small intestine and liver of the rat during development. J Dev Physiol 1:315-327

8. Jones ME 1985 Conversion of glutamate to ornithine and proline: pyrroline5 -carboxylate, a possible modulator of arginine requirements. J Nutr 115:509-515

9. Sallach HJ, Koeppe RE, Rose WC 1951 The in vivo conversion of glutamic acid into proline and arginine. J Am Chem Soc 73:4500(abstr)

10. Smith RJ, Downing SJ, Phang JM, Lodato RF, Aoki TT 1980 Pyrroline-5- carboxylate synthase activity in mammalian cells. Proc Natl Acad Sci USA 77:5221-5225

11. Ross G, Dunn D, Jones ME 1978 Ornithine synthesis from glutamate in rat intestinal mucosa homogenates: evidence for the reduction of glutamate to $\gamma$-glutamyl semialdehyde. Biochem Biophys Res Commun 85:140-147

12. Henslee JG, Jones ME 1982 Ornithine synthesis from glutamate in rat small intestinal mucosa. Arch Biochem Biophys 219:186-197

13. Henslee JG, Wakabayashi Y, Small C, Jones ME 1983 Factors influencing pyrroline 5-carboxylate synthesis from glutamate by rat intestinal mucosa mitochondria. Arch Biochem Biophys 226:693-703

14. Wakabayashi Y, Jones ME 1983 Pyrroline 5-carboxylate synthesis from glutamate by rat intestinal mucosa. J Biol Chem 258:3865-3872

15. Matsuzawa T, Ishiguro I, Hayasaka S, Shiono T, Nakajima H, Mizuno K 1980 Hyperornithinemia with gyrate atrophy and enzymes involved in ornithine metabolism of the eye. Biochem Int 1:179-189

16. Morris JG 1985 Nutritional and metabolic responses to arginine deficiency in carnivores. J Nutr 115:524-531

17. Beaufay H, Bendall DS, Baudhuin P, de Duve C 1959 Intracellular distribution of some dehydrogenases, alkaline deoxyribonucleases and iron in rat-liver tissue. Biochem J 73:623-628

18. Wakabayashi Y, Yamada R, Iwashima A 1984 A one-step assay for pyrroline5-carboxylate synthase using a short AG1-X8 column. J Biochem Biophys Methods 9:185-192

19. Peraino C, Pitot HC 1963 Ornithine transaminase in the rat. 1. Assay and some general properties. Biochim Biophys Acta 73:222-231

20. Siedel ER, Haddox MK, Johnson LR 1984 Polyamines in the response to intestinal obstruction. Am J Physiol 246:G649-G653

21. Lowry OH, Rosebrough NJ, Farr AL, Randall RJ 1951 Protein measurement with the Folin phenol reagent. J Biol Chem 193:265-275

22. Hoogenraad N, Totino N, Elmer H, Wraight C, Alewood P, Basil Johns R 1985 Inhibition of intestinal citrulline synthesis causes severe growth retardation in rats. Am J Physiol 249:G792-G799

23. Nagy LE, Kretchmer $\mathrm{N} 1988$ Utilization of glutamine in the developing rat jejunum. J Nutr 118:189-193

24. Battaglia FC, Meschia G 1978 Principal substrates of fetal metabolism. Physiol Rev 58:499-527

25. Williams-Ashman HG, Canellakis ZN 1979 Polyamines in mammalian biology and medicine. Perspect Biol Med 22:421-453

26. Russel DH 1973 Roles of the polyamines, putrescine, spermidine and spermine in normal and malignant tissues. Life Sci 13:1635-1647

27. Yang P, Baylin SB, Luk G 1984 Polyamines and intestinal growth: absolute requirement for ODC activity in adaptation during lactation. Am J Physiol 247:G553-G557

28. Johnson LR, Tseng CC, Wang P, Tipnis UR, Haddox MK 1989 Mucosal ornithine decarboxylase in the small intestine: localization and stimulation. Am J Physiol 256:G624-G630

29. McNeil N, Eikenburg BE, Johnson LR 1987 Role of ornithine decarboxylase in functional development of rat gastric mucosa. Am J Physiol 252:G466G471

30. Janne J, Holtta E 1973 Putrescine metabolizing enzyme activities in some rat tissue during postnatal development. Acta Chem Scand [B] 27:10-15

31. Ball WJ, Ballis ME 1976 Changes in ornithine decarboxylase activity in rat intestines during aging. Cancer Res 36:3312-3316

32. Luk GD, Marton LJ, Baylin SB 1980 Ornithine decarboxylase is important in intestinal mucosal maturation and recovery from injury in rats. Science 210:195-198 